\title{
Intrarenal ectopic adrenal tissue and renal-adrenal fusion: a report of nine cases
}

\author{
Huihui Ye ${ }^{1}$, Ghil Suk Yoon ${ }^{2,3,4}$ and Jonathan I Epstein ${ }^{2,3,4}$ \\ ${ }^{1}$ Departments of Pathology, New York University Medical Center, New York, NY, USA; ${ }^{2}$ Department of \\ Pathology, The Johns Hopkins University School of Medicine, The Johns Hopkins Hospital, The James Brady \\ Urological Institute, Baltimore, MD, USA; ${ }^{3}$ Department of Urology, The Johns Hopkins University School of \\ Medicine, The Johns Hopkins Hospital, The James Brady Urological Institute, Baltimore, MD, USA and \\ ${ }^{4}$ Department of Oncology, The Johns Hopkins Hospital, The Johns Hopkins University School of Medicine, \\ The James Brady Urological Institute, Baltimore, MD, USA
}

\begin{abstract}
Intrarenal ectopic adrenal tissue and renal-adrenal fusion are rare findings in the adult population. We reviewed seven cases of intrarenal adrenal tissue and two cases of renal-adrenal fusion. Patients ranged in age from 35 to 75 years (mean 55). Ectopic adrenal tissue was identified at the superior pole of the kidney in all but one case, which was located in the mid-portion of the kidney. Ectopic adrenal tissue varied in its growth from subcapsular lesions that were plaque-like $(n=3)$, wedge-shaped $(n=2)$, or spherical $(n=1)$ to irregular nests deep in the renal parenchyma $(n=1)$. In all nine cases, the adherent and intrarenal adrenal tissue was composed of adrenal cortical tissue, with no adrenal medullary tissue present. In six cases, adrenal tissue focally extended into renal parenchyma in an infiltrative manner. Of the nine cases, two were diagnostic problems for the contributing pathologists. In one case, intrarenal adrenal tissue mimicked low-grade clear cell renal cell carcinoma. In another case, an adrenocortical adenoma adherent to the kidney resembled renal invasion by adrenocortical carcinoma. This study summarizes key morphological features of intrarenal ectopic adrenal tissue and renaladrenal fusion along with histological pitfalls and its differential diagnoses.
\end{abstract}

Modern Pathology (2009) 22, 175-181; doi:10.1038/modpathol.2008.162; published online 26 September 2008

Keywords: renal adrenal fusion; ectopic adrenal; intrarenal adrenal

Adrenal tissue can be aberrantly located in the adjacent kidney. Cases of both true ectopic intrarenal adrenal tissue and renal-adrenal fusion have been reported. $^{1-6}$ They are usually discovered incidentally in autopsies and surgical specimens and are of no clinical significance. However, in certain situations, adrenal heterotopia may pose a diagnostic challenge. In this case series, we describe nine cases of intrarenal adrenal tissue and renal-adrenal fusion including two diagnostically problematic cases.

Correspondence: Dr JI Epstein, MD, Department of Pathology, The Johns Hopkins Hospital, The Johns Hopkins University School of Medicine, The James Brady Urological Institute, Johns Hopkins Medical Institution, 401 North Broadway, Weinberg Building, Room 2242, Baltimore, MD 21231, USA.

E-mail: jepstein@jhmi.edu

Received 21 March 2008; revised 18 July 2008; accepted 19 July 2008; published online 26 September 2008

\section{Materials and methods}

From 1994 to 2007, nine cases of intrarenal adrenal tissue were diagnosed at the Johns Hopkins Hospital. Among them, five cases were received in consultation from outside institutions and four were in-house cases. Hematoxylin and eosin-stained slides as well as immunohistochemical stains performed at outside institutions were reviewed.

\section{Results}

A total of nine cases were reviewed, including seven cases of intrarenal ectopic adrenal tissue and two cases of renal-adrenal fusion. Patients ranged in age from 35 to 75 years (mean 55; Table 1). Bilateral adrenal glands were reported as unremarkable in all preoperative MRI or CT studies. Ectopic adrenal tissue was identified at the superior pole of the kidney in all but one case (case 4), which was located in the mid-portion of the kidney. Seven cases were incidentally identified in radical nephrectomy specimens removed for other reasons (Table 1). One of the exceptions included one case 
Table 1 Patient demographics, specimen type, anatomic location, and pathologic diagnosis

\begin{tabular}{|c|c|c|c|c|c|c|c|}
\hline Case & Age & Sex & Specimen & Side & Location & Size & Pathological diagnosis \\
\hline 1 & 44 & M & $\begin{array}{l}\text { Transplant } \\
\text { nephrectomy }\end{array}$ & l & N/A & Microscopic & $\begin{array}{l}\text { Cortical necrosis and ATN; } \\
\text { ectopic adrenal tissue with focal necrosis }\end{array}$ \\
\hline 2 & 35 & $\mathrm{~F}$ & Nephrectomy & $\mathrm{R}$ & Upper pole & $0.8 \mathrm{~cm}$ cyst & $\begin{array}{l}\text { Hydronephrosis with chronic pyelonephritis; } \\
\text { intrarenal adrenal gland tissue with adjacent } \\
\text { simple renal cyst }\end{array}$ \\
\hline 3 & 55 & $\mathrm{~F}$ & Donor kidney biopsy & $\mathrm{L}$ & N/A & $0.3 \mathrm{~cm}$ & Intrarenal adrenal rest \\
\hline 4 & 75 & M & Radical nephrectomy & $\mathrm{L}$ & Mid-portion & 'A small amount' & $\begin{array}{l}\text { Clear cell RCC; } \\
\text { a small amount of adrenal tissue } \\
\text { adherent to the medial renal capsule }\end{array}$ \\
\hline 5 & 72 & M & Radical nephrectomy & $\mathrm{R}$ & Upper pole & $0.7 \mathrm{~cm}$ & $\begin{array}{l}\text { Non-invasive papillary UC; } \\
\text { adjacent CIS; A small subcapsular } \\
\text { adrenal rest }\end{array}$ \\
\hline 6 & 51 & M & Radical nephrectomy & $\mathrm{L}$ & Upper pole & 'A small portion' & $\begin{array}{l}\text { Papillary RCC; } \\
\text { renal--adrenal fusion }\end{array}$ \\
\hline 7 & 52 & $\mathrm{~F}$ & $\begin{array}{l}\text { Laparoscopic } \\
\text { nephrectomy }\end{array}$ & $\mathrm{L}$ & N/A & Microscopic & $\begin{array}{l}\text { End-stage kidney; } \\
\text { ectopic adrenal tissue in renal capsule } \\
\text { and cortex }\end{array}$ \\
\hline 8 & 49 & $\mathrm{~F}$ & Partial nephrectomy & $\mathrm{L}$ & Upper pole & $2 \times 2 \times 1 \mathrm{~cm}$ & $\begin{array}{l}\text { Cortical adenoma arising in adherent and } \\
\text { intrarenal adrenal gland }\end{array}$ \\
\hline 9 & 59 & $\mathrm{~F}$ & Radical nephrectomy & $\mathrm{R}$ & Upper pole & $1.5 \mathrm{~cm}$ cyst & $\begin{array}{l}\text { Low-grade RCC, NOS; small focus of } \\
\text { ectopic adrenal tissue }\end{array}$ \\
\hline
\end{tabular}

ATN, acute tubular necrosis; CIS, urothelial carcinoma in situ; L, left; R, right; M, male; F, female; N/A, not available; NOS, not otherwise specified; RCC, renal cell carcinoma; UC, urothelial carcinoma.

Table 2 Summary of morphologic findings

\begin{tabular}{|c|c|c|c|c|c|c|c|c|}
\hline Case & Location & Shape & Capsule & Zonation & $\begin{array}{l}\text { Aberrant blood } \\
\text { vessels }\end{array}$ & $\begin{array}{l}\text { Scattered } \\
\text { adipocytes }\end{array}$ & $\begin{array}{l}\text { Focal infiltrative } \\
\text { growth }\end{array}$ & $\begin{array}{l}\text { Entrapped } \\
\text { renal tubules }\end{array}$ \\
\hline 1 & Subcap & Plaque & No & None & No & Yes & Yes & No \\
\hline 2 & Deep and cystic wall & Irregular & No & None & Yes & No & Yes & Yes \\
\hline 3 & Subcap & Spherical & Yes & Maintained & No & No & No & Yes \\
\hline 4 & Subcap & Plaque & Focal & None & No & Yes & Yes & No \\
\hline 5 & Subcap & Wedge & No & None & Yes & Yes & No & Yes \\
\hline 6 & RA fusion & Crescent & Focal & Maintained & No & Yes & Yes & Yes \\
\hline 7 & Subcap and extracap & Wedge & No & None & Yes & No & Yes & Yes \\
\hline 8 & RA fusion & Spherical & Focal & Partially & No & No & Yes & Yes \\
\hline 9 & Subcap and cystic wall & Plaque & Focal & None & No & No & No & No \\
\hline
\end{tabular}

Extracap, extracapsular; RA, renal-adrenal; Subcap, subcapsular.

(case 8) of an adrenal cortical adenoma arising in the setting of renal-adrenal fusion, clinically suspected to be a renal mass by imaging studies, and resected by partial nephrectomy. The other case, which was not incidentally found, was a donor kidney tissue biopsy submitted for frozen section diagnosis during kidney transplantation (case 3). Among the seven total nephrectomy cases, adherent adrenal gland or ectopic adrenal tissue was identified grossly in four cases, microscopically in sections of simple renal 

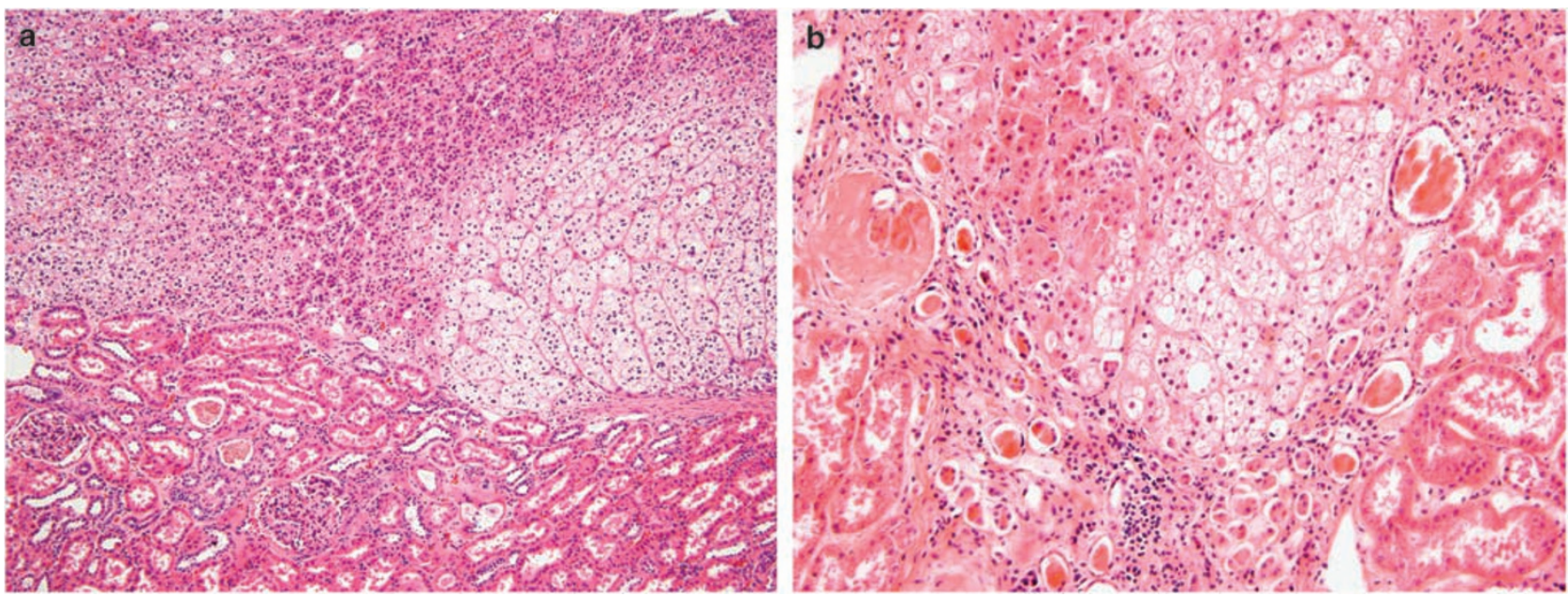

Figure 1 Adrenal tissue in direct contact with renal cortex with no intervening fibrous capsule (a). Focally, adrenal tissue extended into renal cortex in an infiltrative manner (b).
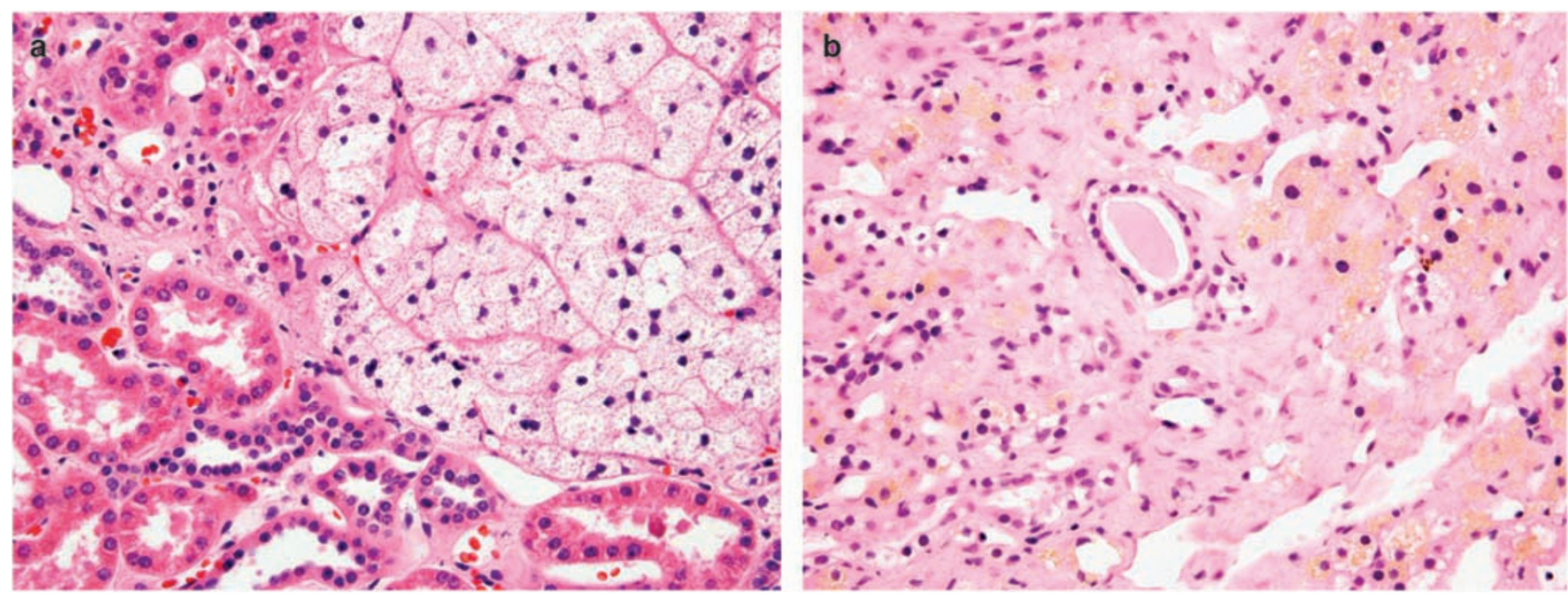

Figure 2 Case 8. microvesicular cytoplasm of zona fasciculata cells (a). Brown lipofuscin granules present in zona reticularis cells. Note the entrapped renal tubule in the center $(\mathbf{b})$.
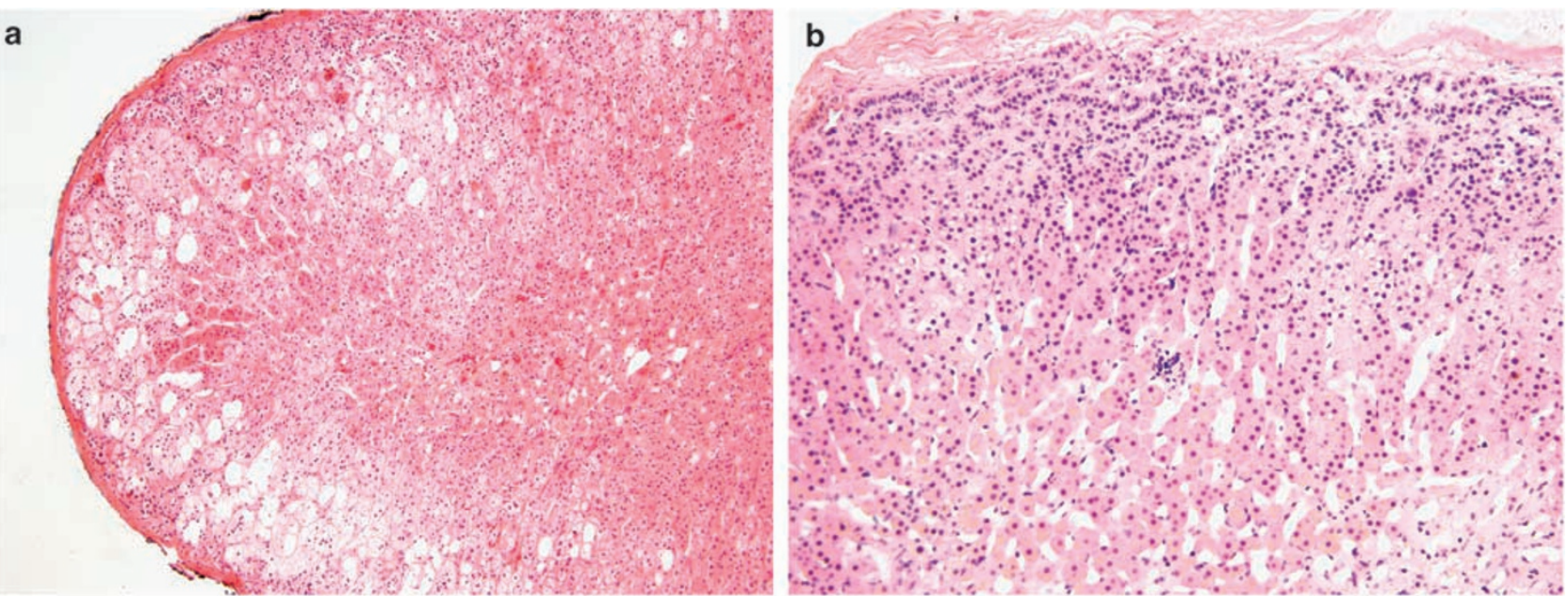

Figure 3 Case 6. normal architecture of adrenal gland in renal-adrenal fusion (a). Case 3, normal adrenal architecture was well maintained in subcapsular ectopic adrenal tissue (b). 


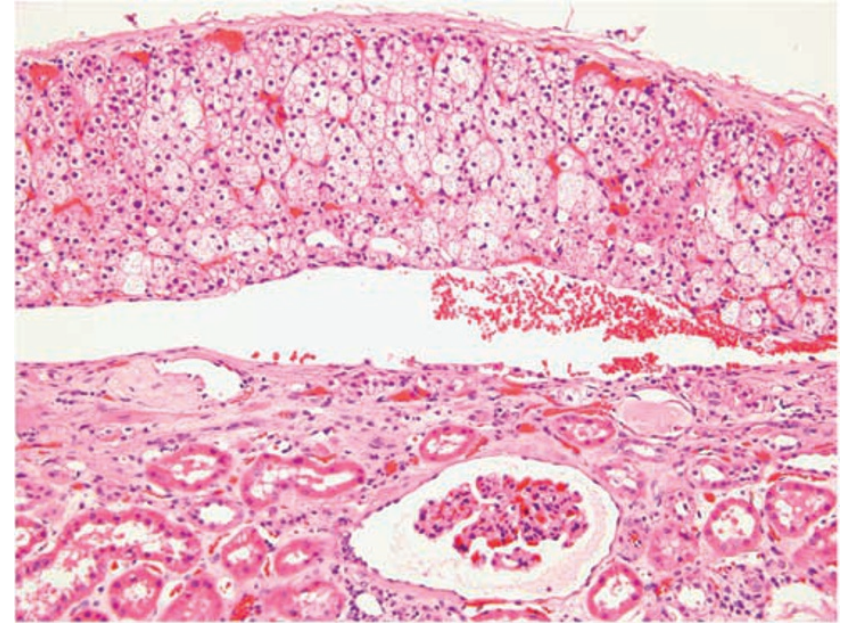

Figure 4 Lack of normal architecture of adrenal gland in renal-adrenal fusion. cysts in two cases, and microscopically in random sections of two cases (Table 1).

Ectopic adrenal tissue varied in its growth from subcapsular lesions that were plaque-like $(n=3)$, wedge-shaped $(n=2)$, or spherical $(n=1)$ to irregular nests deep in the renal parenchyma $(n=1)$ (Table 2 ). In all nine cases, the adherent and intrarenal adrenal tissue was composed of adrenal cortical tissue, with no adrenal medullary tissue present. At the base of the subcapsular adrenal tissue, a complete fibrous septum separating the adrenal tissue from the renal parenchyma was present in only one case with incomplete septa in four cases. In the remaining four cases lacking a fibrous septum, nests of clear cells or eosinophilic cells were in direct contact with the renal parenchyma (Figure 1a). In six cases, adrenal tissue focally extended to renal parenchyma in an infiltrative manner (Figure 1b). Entrapped atrophic renal tubules were commonly seen at the periphery
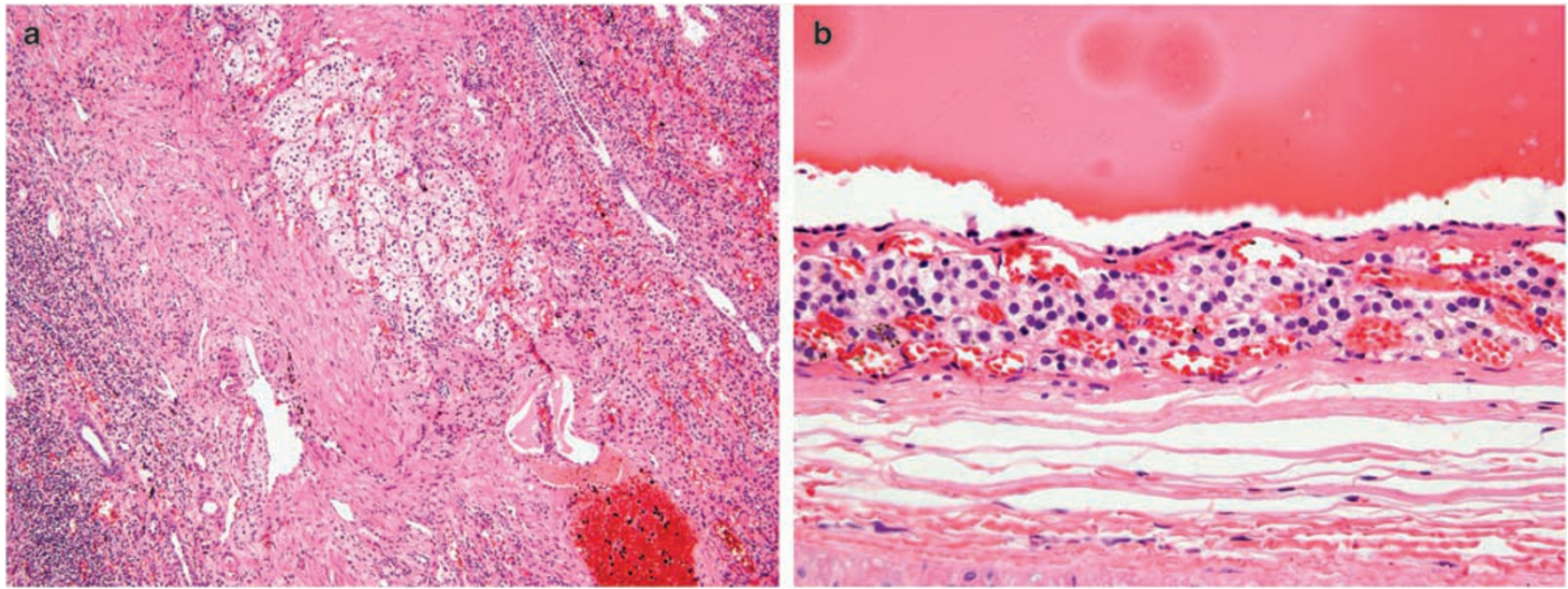

Figure 5 Case 2. irregular solid nests of clear cells deep in renal parenchyma (a). Clear cells also noted in the wall of a simple renal cyst, with prominent vascular network similar to that seen in clear cell renal cell carcinoma (b).
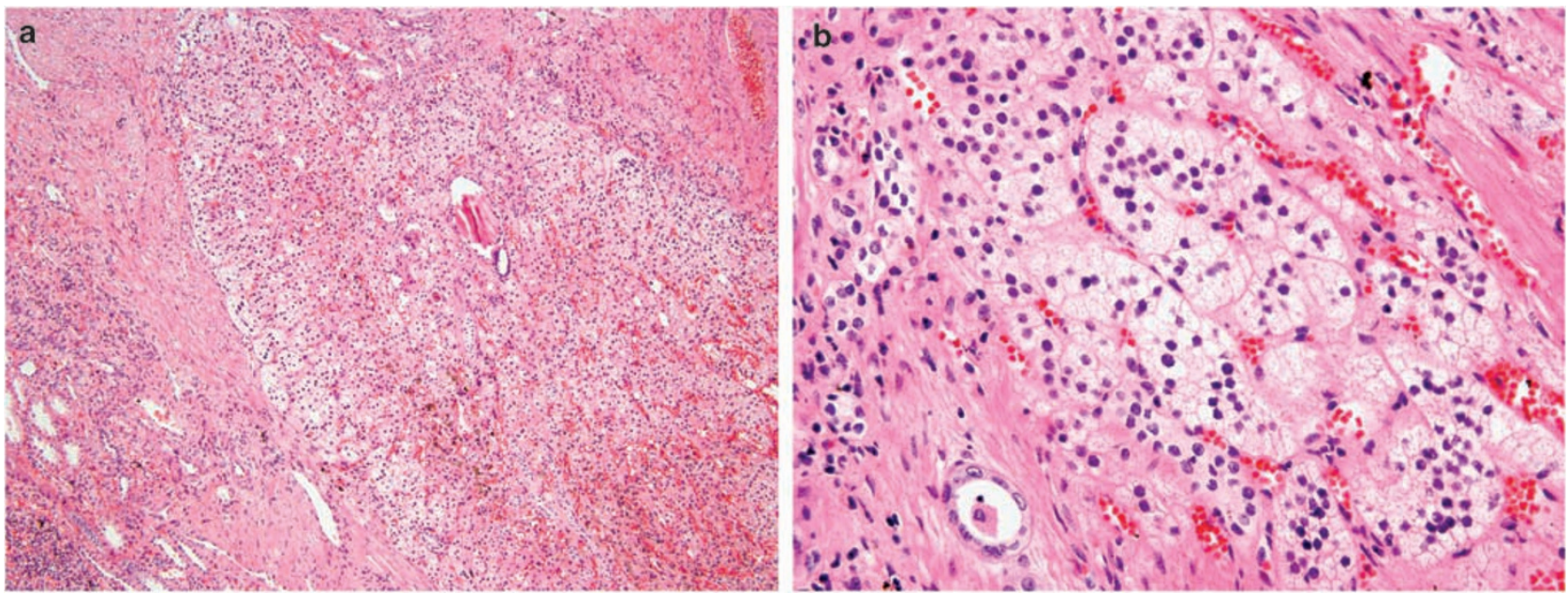

Figure 6 Case 2. vague zonal distribution (a). High magnification reveals microvesicular cytoplasm of the clear cells (b). 

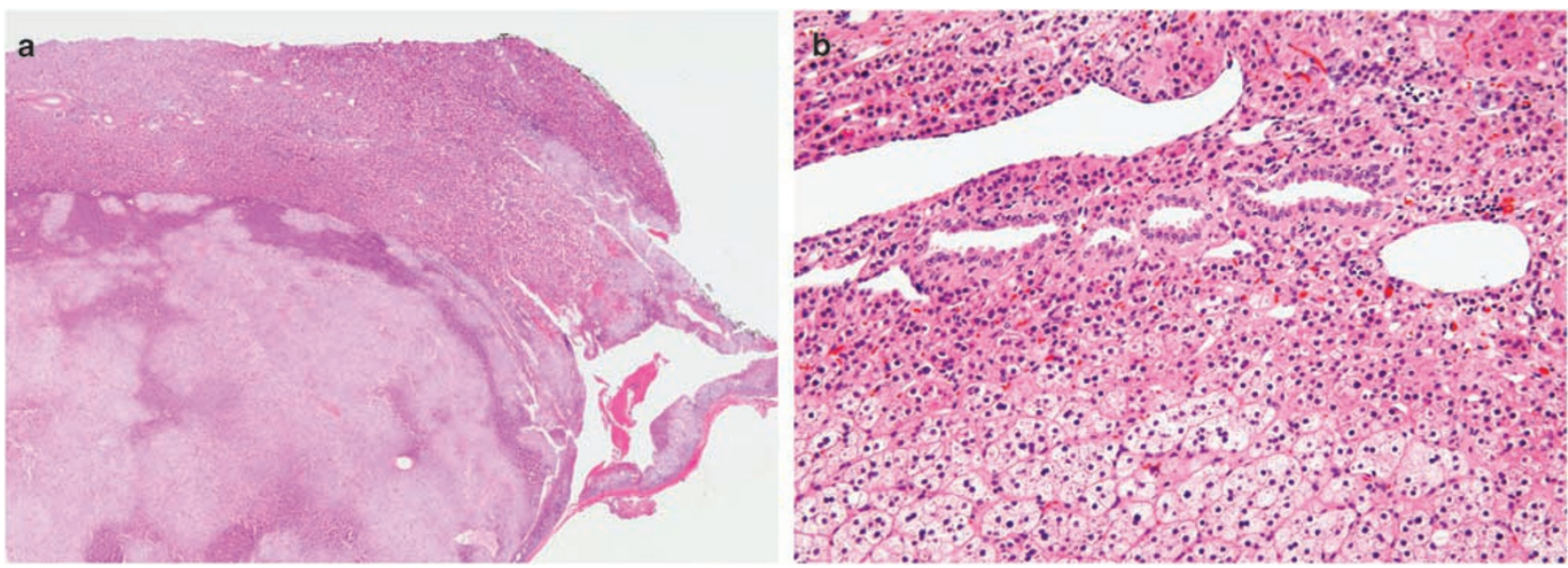

Figure 7 Case 8. Adrenal cortical adenoma arising from renal-adrenal fusion in direct contact with renal cortex (a). Entrapped renal tubules in cortical adenoma arising from renal-adrenal fusion (b).

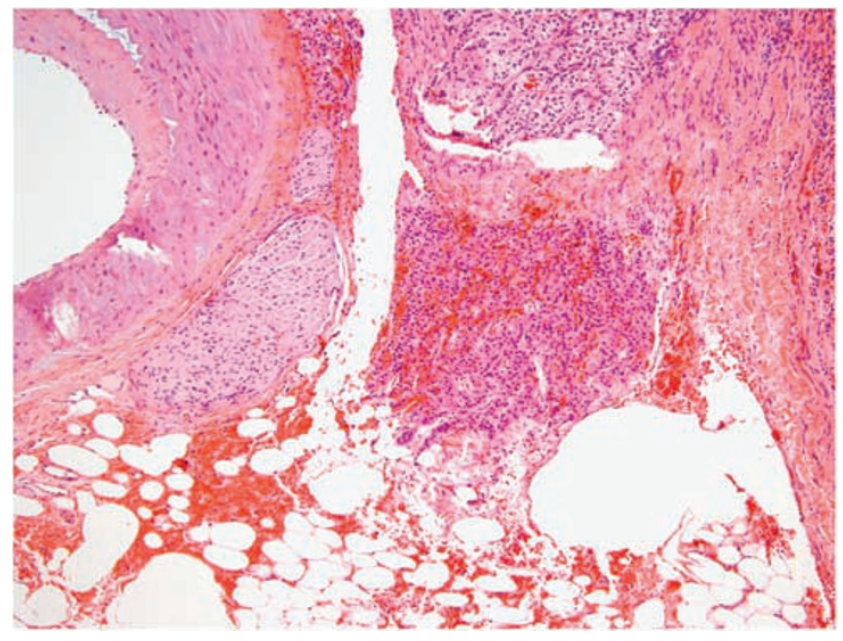

Figure 8 Ectopic adrenal tissue extends from subcaspular region into perirenal adipose tissue without a surrounding fibrous capsule.

of ectopic adrenal tissue, at the interface of renal tissue. In six cases, entrapped renal tubules were focally present deeper in the parenchyma of the ectopic adrenal tissue, away from the renal-adrenal junction (Figure 2b; Table 2).

In two cases of renal-adrenal fusion (cases 6 and 8) and one intrarenal ectopia case (case 3), normal adrenal architectures were well maintained, and one was able to identify the three zones of cortical cells (Figure 3a and b; Table 2). Zona glomerulosa cells (the outermost layer) were located beneath the renal capsule. They were relatively small cells with faintly eosinophilic or amphophilic cytoplasm organized in small clusters and short trabeculae. Nuclei were round to oval, with a high nuclear-to-cytoplasmic ratio. Away from the capsule, were zona fasciculata cells composed of large cells arranged in two-cellwide cords with parallel running capillaries in between cords. At high magnification, these cells had centrally located round nuclei and characteristic abundant microvesicular or spongy cytoplasm filled with lipid droplets (Figure 2a). Deeper to zona fasciculata, zona reticularis cells were arranged in one-cell-wide rows haphazardly arranged. The cells had granular eosinophilic cytoplasm where yellow to light brown lipofuscin pigment was commonly present (Figure 2b).

In the remaining six cases, ectopic adrenal tissue lost its normal architecture (Table 2). In five cases $(1,4,5,7$, and 9), only two types of adrenal cortical cells were discernable. Small-to-intermediate solid nests or trabeculae of clear cells and eosinophilic cells with an intervening capillary network were intermixed randomly without obvious zonation. It was difficult to determine whether the eosinophilic cells were from the zona glomerulosa or reticularis. In such instances, low-grade renal cell carcinoma, clear cell type, with eosinophilic cell features, could enter into the differential diagnosis (Figure 4). Case 2 was most difficult to diagnose because it consisted of irregular islands of clear cells deep in the renal parenchyma in a kidney resected for hydronephrosis with chronic pyelonephritis. In addition, clusters of clear cells were found lining a simple renal cyst. A delicate capillary network separated the clear nests, just as in clear cell renal cell carcinoma (Figure 5a and b). Immunohistochemical studies were performed at the outside hospital, as a suspicion of clear cell renal cell carcinoma was raised. The clear cells lacked immunoreactivity for epithelial markers (pan-keratin, CAM5.2, and EMA) and the histiocytic marker CD68. The outside hospital diagnosis was 'focal atypical clear cells, suspicious for clear cell renal cell carcinoma'. Focally, there was a solid cluster of cells with a vaguely zonal architecture (Figure 6a). The outer layers were large clear cells resembling zona fasciculata. The inner layers were slightly eosinophilic small cells arranged in vague cords resembling zona reticularis. The adjacent nests of clear cells, although lacking a zonal pattern, were 

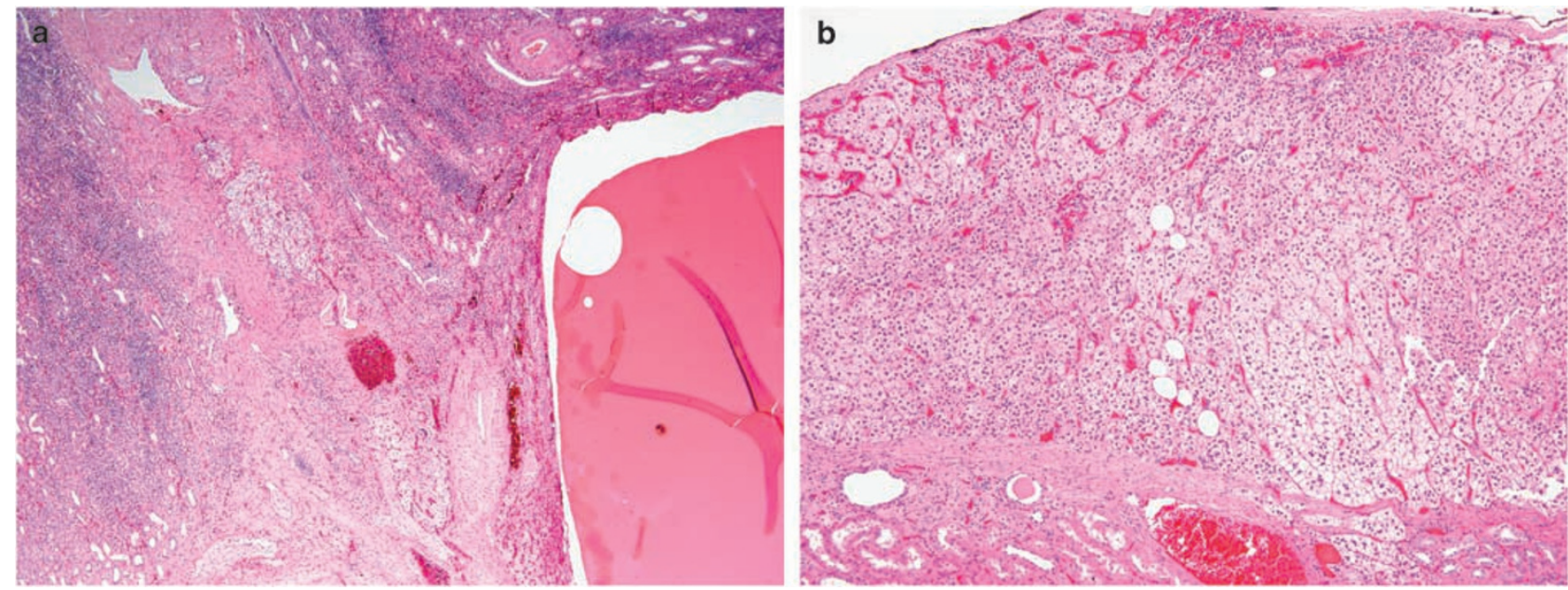

Figure 9 Case 2. Deformed blood vessels intertwined with ectopic adrenal tissue in deep renal parenchyma (a). Scattered adipocytes in subcapsular ectopic adrenal tissue in case 4 (b).

identical cytologically to the clear cells in the area with zonation. More importantly, the large clear cells had a characteristic microvesicular pattern, which differed from the dissolved empty cytoplasm of clear cell renal cell carcinoma (Figure 6b). The cells had uniformly small round nuclei with no cytological atypia or prominent nucleoli.

A unique diagnostic problem was posed in another case. In case 8, a 2-cm adrenal cortical adenoma was found arising from the adrenal gland attached to the superior pole of the ipsilateral kidney. The adenoma was nonfunctional and was found incidentally on imaging studies. It was mainly composed cells resembling zona fasciculata and zona glomerulosa in roughly equal amounts. An incomplete fibrous capsule separated most of the adjacent adrenal gland and part of the adenoma from the kidney. A part of the adrenal adenoma was unencapsulated and in direct contact with the renal cortex (Figure 7a). Focally, several renal tubules were entrapped deep in the parenchyma of the adrenal adenoma (Figure 7b). A question was raised at the outside hospital whether the adrenal cortical neoplasm was an adenoma or carcinoma because of the 'penetration and focal invasion' of the adenoma into renal cortical parenchyma.

\section{Discussion}

Renal-adrenal fusion was first described by Rokitansky $^{7}$ who subclassified this entity into a developmental form and postinflammatory fibrosis type. The developmental mechanism underlying renal-adrenal fusion is thought to be a failure of retroperitoneal mesenchyme to stimulate capsule formation. As a result, separate encapsulation of adrenal gland and kidney is impeded, promoting fusion. ${ }^{5}$ Renal-adrenal fusion is typically more of a diagnostic problem for radiologists than for pathologists. Adherent adrenal glands can be radiologically misdiagnosed as renal masses leading to unnecessary resections. ${ }^{1}$ In rare occasions, renaladrenal fusion can also pose diagnostic problems for pathologists. One case report describes a $12-\mathrm{cm}$ pseudocyst arising from the renal-adrenal fusion that was mistaken for a cystic renal mass on imaging studies. $^{2}$ An intraoperative frozen section biopsy was performed, where the differential diagnosis included adrenal lesion and cystic renal cell carcinoma, as clear cells were noted in the cystic wall. The correct diagnosis was made on the nephrectomy specimen, in which an adrenal gland was grossly identified. ${ }^{2}$ In this study, one of our cases of renal-adrenal fusion with an adrenal cortical adenoma led to the histological differential diagnosis of an adrenal cortical carcinoma invading the renal parenchyma. However, the adenoma lacked features of malignancy other than the questioned renal invasion. The cells had no cytologic atypia, and were not mitotically active, lacked necrosis, and showed no lymphovascular invasion. The adjacent normal adrenal gland was adherent to the kidney and shared a discontinuous common capsule with the kidney.

Ectopic adrenal tissue is thought to be a distinct anomaly from renal-adrenal fusion. It is estimated to occur in about $1 \%$ of the adult population and up to $50 \%$ of neonates. Ectopic adrenal tissue usually regresses in early infancy. ${ }^{3}$ The adrenal cortex is developed from the coelomic mesoderm of the urogenital ridge during the 5th week of gestational age and separates from it during the 8th week. Ectopic adrenal tissue occurs when a fragment of the primitive adrenal gland sheds off during development. It may rest in any visceral organs, more frequently in the kidney, liver, and gonads. Ectopic adrenal tissue may contain both cortex and medulla, if the breaking event occurs after migration of neural 
crest tissue into the cortex, or may contain cortex only if the breaking occurs before junction of the medulla and cortex. ${ }^{8,9}$ All seven cases of intrarenal adrenal tissue in this study contained only cortical tissue. Ectopic adrenal tissue is usually found incidentally in surgical specimens or at autopsy, with no clinical significance. Rarely, ectopic adrenal tissue can become clinically significant, if it gives rise to tumors (ie, cortical adenoma or carcinoma).

Most cases of intrarenal adrenal tissue are also not a diagnostic challenge for pathologists. Intrarenal adrenal tissue is usually located in subcapsular regions in the superior poles of kidney, with wellmaintained low power architecture of normal adrenal glands. However, cases can be difficult, if ectopic adrenal gland is located deep in renal parenchyma, or loses its normal architecture or its three cell types. Fromer et $a l^{6}$ reported an unusual case of nonencapsulated intrarenal adrenal tissue in bilateral cadaveric donor kidneys. ${ }^{6}$ Intraoperative frozen section analysis was performed. Both lesions were interpreted as 'small oncocytic tumor, chromophobe renal cell carcinoma cannot be excluded', leading to the removal of both kidneys from the two transplant recipients. Final pathological analysis diagnosed intrarenal adrenal tissue, with the assistance of immunohistochemical studies for EMA, cytokeratin, and inhibin. ${ }^{6}$ When intrarenal adrenal tissue is composed of predominantly clear cells, it may mimic low-grade clear cell renal cell carcinoma as both adrenal tissue and clear cell renal cell carcinoma contain a delicate intervening vascular network. This study highlights additional potential histological pitfalls. First, ectopic adrenal tissue can be compressed by an adjacent simple renal cyst, as in cases 2 and 9, where the presence of clear cells in the cyst wall mimics cystic renal cell carcinoma. Second, ectopic adrenal tissue can extend beyond the renal capsule into perirenal adipose tissue without a surrounding fibrous capsule, as in case 7, mimicking extracapsular extension of renal cell carcinoma (Figure 8).

Morphologic features supporting the diagnosis of adrenal cortical tissue include at least focally maintained adrenal architecture and cell differentiation, lack of cytologic atypia, no necrosis, no lymphovascular invasion, and characteristic spongy cytoplasm filled with lipid droplets in the clear cells resembling cells of the zona fasciculata. Intrarenal ectopic adrenal tissue in this study had two unique features typically not seen in renal cell carcinoma. Intermediate-to-large caliber blood vessels with thick smooth muscle layers were observed in three cases of ectopic adrenal tissue (Figure 9a). The other observation was scattered adipocytes in ectopic adrenal tissue ( $n=4$; Figure $9 \mathrm{~b})$. Immunohistochemical markers can help resolve the differential diagnosis. Adrenal cortical tissue is usually positive for inhibin, Melan A, and negative for RCC, CD10, EMA, and pancytokeratin with the opposite pattern for clear cell renal cell carcinoma. ${ }^{10,11}$

In summary, ectopic adrenal tissue and renaladrenal fusion are rare findings with a spectrum of morphologic features. Lesions can range from subcapsular obvious adrenal tissue with zonation and normal adrenal architecture to deeply located solid nests of predominantly clear cells with no zonation mimicking low-grade clear cell renal cell carcinoma. In most cases, the correct diagnosis can be made by morphologic features alone with ancillary use of immunohistochemical studies in problematic cases. Rarely, neoplasms can arise in ectopic adrenal tissue or in cases of renal-adrenal fusion, where involvement of the kidney should not be mistaken for malignancy in an adrenocortical neoplasm.

\section{References}

1 Colberg JW, Cai X, Humphrey PA. Unilateral adrenal heterotopia with renal-adrenal fusion. J Urol 1998;160:116.

2 Fan F, Pietrow P, Wilson LA, et al. Adrenal pseudocyst: a unique case with adrenal-renal fusion, mimicking a cystic renal mass. Ann Diagn Pathol 2004;8:87-90.

3 Souverijns G, Peene P, Keuleers H, et al. Ectopic localisation of adrenal cortex. Eur Radiol 2000;10:1165-1168.

4 Mitchell N, Angrist A. Adrenal rests in the kidney. Arch Path 1943;35:46-52.

5 Honore LH, O’Hara KE. Combined adrenorenal fusion and adrenohepatic adhesion: a case report with review of the literature and discussion of pathogenesis. J Urol 1976;115:323-325.

6 Fromer DL, Birkhoff JD, Hardy MA, et al. Bilateral intrarenal adrenal glands in cadaveric donor kidneys resembling renal cell carcinoma on intraoperative frozen section. J Urol 2001;166:1820-1821.

7 Rokitansky K. A manual of Pathological Anatomy, Vol. Part II, Blanchard: Philadelphia, 1855, 188pp.

8 Sadler TW. Langman's Medical Embryology, 10th edn, Lippincott Williams and Wilkins: Baltimore, MD, 2006, 68-72, 314-315.

9 Moore KL, Persaud TVN. The Developing Human, 7th edn, Saunders: Philadelphia, 2003, 288-306.

10 Pan CC, Chen PC, Tsay SH, et al. Differential immunoprofiles of hepatocellular carcinoma, renal cell carcinoma, and adrenocortical carcinoma: a systemic immunohistochemical survey using tissue array technique. Appl Immunohistochem Mol Morphol 2005;13:347-352.

11 Fetsch PA, Powers CN, Zakowski MF, et al. Anti-alphainhibin: marker of choice for the consistent distinction between adrenocortical carcinoma and renal cell carcinoma in fine-needle aspiration. Cancer 1999;87:168-172. 